\title{
Results of Clinical Evaluations of Filipino Patients with Mucopolysaccharidosis Type II (Hunter Syndrome) in a One Stop Multidisciplinary Clinic at the Philippine General Hospital: a 3-Year Experience
}

\author{
Mary Anne D. Chiong, 1,2 April Grace D. Berboso,,$^{1,2}$ Melissa Mae P. Baluyot ${ }^{1,2}$ and Mary Ann R. Abacan ${ }^{1,2}$ \\ ${ }^{1}$ Section of Clinical Genetics, Department of Pediatrics, College of Medicine and Philippine General Hospital, University of the Philippines Manila \\ 2Institute of Human Genetics, National Institutes of Health, University of the Philippines Manila
}

\begin{abstract}
Mucopolysaccharidosis type II (Hunter syndrome), a rare X-linked recessive disorder due to a deficiency of lysosomal enzyme iduronate-2-sulfatase (I2S), is a chronic and progressive disorder with variable age of onset and rate of progression. The manifestations are multisystemic, and management should involve a multidisciplinary approach. In 2009, the Philippine General Hospital began conducting biannual clinics tailored for patients with Hunter syndrome. Review of the clinical findings in Filipino patients with MPS II showed that the most common presenting signs were coarse facial features. The mean age of confirmation of diagnosis was 5 years of age. Sixty seven percent (67\%) of our patients had the severe phenotype. All presented with short stature and majority had hepatosplenomegaly, characteristic skeletal and joint abnormalities and upper airway disease. Most also had valvular defects as well as visual problems. The number and severity of clinical manifestations among our patients did not show a significant correlation with the levels of urinary GAGs nor with the iduronate-2-sulfatase (I2S) activity. Despite the lack of availability of enzyme replacement therapy for this disorder in our country, the regular subspecialty evaluations, concomitant symptomatic treatment, supportive care and counseling being provided by the multidisciplinary clinic help these children and their families in coping with their illness and reassure them of a continued partnership with the medical team.
\end{abstract}

\section{Introduction}

Mucopolysaccharidosis type II (MPS II), also known as Hunter syndrome is a rare $\mathrm{X}$-linked recessive disorder caused by a deficiency of the lysosomal enzyme iduronate-2sulfatase (I2S), which catalyzes the step in the catabolism of glycosaminoglycans. In patients with Hunter syndrome, the glycosaminoglycans dermatan sulfate and heparan sulfate accumulate within the lysosomes and cells contributing to multi-organ pathologies. It is one of the commonest

Corresponding author: Mary Anne D. Chiong, MD

Department of Pediatrics

Philippine General Hospital

University of the Philippines Manila

Taft Avenue, Ermita, Manila 1000 Philippines

Telephone: +6325240892

Email: maryannechiong@gmail.com mucopolysaccharidoses with an incidence of approximately 1 in 170,000 male live births. ${ }^{1}$ In the Philippines, the total prevalence has not been established yet but there are 25 patients collected in the local registry (Institute of Human Genetics, National Institutes of Health).

Hunter syndrome is a chronic and progressive disorder with a variable age of onset and rate of progression. Common presenting features include facial dysmorphism, organomegaly, joint stiffness and contractures, pulmonary dysfunction, myocardial enlargement and valvular dysfunction, neurologic involvement and excess urinary glycosaminoglycan excretion. ${ }^{1}$

The phenotypic expression of the disorder should be regarded as a continuum in terms of clinical severity. At the more severe end of the continuum, symptoms appear between 2 and 4 years of age with prominent progressive neurologic involvement and mental retardation. At this end of the spectrum, death occurs in the first or second decade of life, typically due to obstructive airway disease and/or cardiac failure associated with the loss of neurologic function. In the more attenuated form of the disease, clinical signs and symptoms have a later onset. However, it is important to note that individuals who are diagnosed with an attenuated form of the disease may still have symptoms and complications that lead to significant morbidity and disability and may present with mild to moderate learning difficulties. ${ }^{1}$

Because the manifestations of Hunter syndrome are multisystemic with some aspects that are clearly life threatening, the management of the disease demands that the physician be aware of the full range of issues surrounding a patient with Hunter syndrome and that a multidisciplinary approach be implemented. ${ }^{2}$ Management should be centralized in major medical centers with access to a broad range of medical specialties.

Enzyme Replacement Therapy (ERT) with recombinant idronate-2-sulfatase is commonly used to treat MPS II in over 50 countries worldwide. Reported early responses include an enhanced feeling of well being and "greater energy", near-normalization of urinary GAG levels, 
reduction in the sizes of liver and spleen, and improvement in soft tissue joint contractures, 6-minute walk distance and pulmonary function tests. As currently formulated and administered, ERT is not expected to cross the blood brain barrier and therefore would not be expected to lead any major improvement in CNS dysfunction seen in patients with severe MPS II.

Alternative therapies such as stem cell transplantation using umbilical cord blood, peripheral blood hematopoietic cells or bone marrow have also been attempted, but they appear to offer limited clinical benefits in patients in this disease and have been associated with a serious risk of morbidity and mortality. ${ }^{3,4}$

Given the economic situation in the Philippines and the lack of government support for specific treatment of rare diseases such as MPS II, access to available treatment such as ERT is not a reality at present. Thus, the management of our patients mainly relies on supportive symptomatic treatment from a wide variety of specialists.

In 2009, a "one stop" multidisciplinary clinic for patients with MPS II was set up at the Philippine General Hospital. This clinic runs for half a day and includes specialties from cardiology, pulmonology, anesthesia, pediatric surgery, rehabilitation medicine, neurology, developmental pediatrics, ophthalmology, otorhinolaryngology and genetics. A comprehensive initial assessment of each patient at diagnosis is undertaken, and followed by regular reviews every six (6) months.

This paper presents the findings in 15 Filipino patients with MPS II followed up in this multidisciplinary clinic over the past 3 years.

\section{Results of Clinical Evaluations}

All the 15 patients who were regularly seen in the multidisciplinary clinic were males. The diagnosis was confirmed biochemically, after presentation with typical clinical features, by determination of glycosaminoglycan levels in the urine and plasma enzyme assay of the iduronate 2 sulfatase (courtesy of National Taiwan University Hospital). All had elevated total urinary GAG excretion ranging from $145.35 \mathrm{mgGAGs} / \mathrm{gm}$ creatinine to 778.6 mgGAGs/gm creatinine with a mean of 461.2 mgGAGs/gm creatinine that was approximately 13 times higher than the normal. All had low plasma enzyme activity in the blood which ranged from 0.01 to $3.02 \mathrm{nnmol} / \mathrm{mg}$ Prot/4hrs (mean: $0.64 \mathrm{nnmol} / \mathrm{mg}$ Prot/4hrs).

The age of onset ranged from 1 month to 7 years of age. Forty percent $(40 \%)$ of the patients presented with coarse facial features. Other clinical findings, in order of decreasing incidence were joint stiffening (27\%), inguinal hernia (13\%), recurrent upper respiratory tract infection (6.7\%), and developmental delay (6.7\%) (Figure 1).

The age at presentation ranged from 1 month to 7 years old with a mean age of 3 years old. The mean age at confirmation of the disease was 5 years old. The youngest seen in the clinic was 1 year old and oldest was 22 years of age with a mean age first seen at the outpatient clinic of 7 years and 8 months old. One patient underwent screening at 7 months of age because his older sibling was diagnosed earlier.

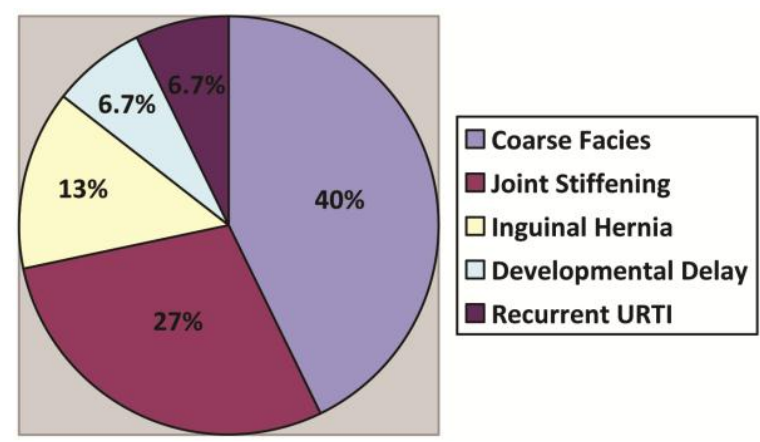

Figure 1. Presenting symptoms of different patients with Mucopolysaccharidosis Type II.

\section{Physical appearance}

All patients had coarsening of facial features which became apparent between the ages of 1 to 6 years old. Specifically, they developed a broad nose with flared nostrils; and thickened alae nasi, ear lobules, lips and tongues. None had plethora of the cheeks or classic peg shaped teeth. Facial and body hypertrichosis were seen in the majority of the patients, as was a protuberant abdomen. The characteristic pearly papular skin eruptions were seen in $40 \%$ of the patients. Most had thick inelastic skin. All had short stature (Table 1, Figures 2 and 3).

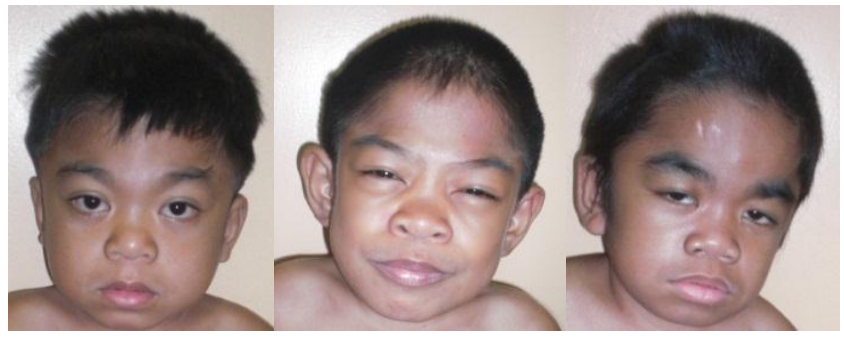

Figure 2. Photographs demonstrating coarse facies of patients with Mucopolysaccharidosis Type II (Note the broad nose with flared nostrils, large jowls and thick lips) [Photographs are published with consent].

\section{Central and peripheral nervous system involvement}

Global developmental delay was evident among our patients early on at $86.7 \%$ (Table 2). The mental impairment was profound and progressive in 4 patients, and unclassified in 9 patients due to lack of neuropsychological data. Two patients were classified as being developmentally at risk. Developmental regression was seen in 3 patients aged 10-12 years of age. 
Three patients had seizures which were controlled with anti-epileptic medications.

Behavioral problems such as hyperactivity (2 patients) and autistic spectrum disorder (1 patient) were also reported.

None had symptoms of spinal cord compression clinically. However, none had undergone imaging of the spine. Three patients (20\%) had symptoms of carpal tunnel syndrome but none had undergone nerve conduction studies and no surgical decompression procedures were suggested at this time (Table 2). One patient had a normal cranial imaging study while another patient showed nonspecific subcortical hypodensities (which could be suggestive of vascular ischemic changes), cerebral atrophy and mild hydrocephalus. The rest did no undergo cranial imaging studies as of the present time.

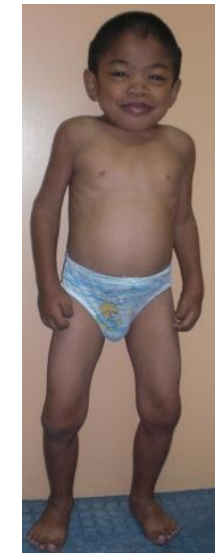

Figure 3. Photograph showing a 13-year-old patient with MPS II with short stature coarse facies and multiple joint contractures) [Photograph published with consent].

Table 1. Baseline Data Mucopolysaccharidosis Type II Patients

\begin{tabular}{|c|c|c|c|c|c|c|}
\hline & $\begin{array}{c}\text { Presenting } \\
\text { Sign/Symptom }\end{array}$ & $\begin{array}{c}\text { Age at } \\
\text { Presentation }\end{array}$ & $\begin{array}{l}\text { Age at Confirmatory } \\
\text { Examination }\end{array}$ & Plasma Enzyme Assay & Urine GAGs & $\begin{array}{c}\text { Age first seen at } \\
\text { the Out Patient } \\
\text { Clinic }\end{array}$ \\
\hline 1 & Coarsening features & 3 years & 6 years 2 months & $\begin{array}{l}\text { Leukocyte } \\
\alpha \text {-iduronase } 40.13(\mathrm{NV}>39.7) \\
\alpha \text {-iduronate sulfatase } 0.28(\mathrm{NV}>18) \\
\beta \text {-galactosidase } 546.23(\mathrm{NV}>97.9)\end{array}$ & $\begin{array}{l}238.0952 \mathrm{mg} \text { GAGs/g crea } \\
\text { (NV 35.74) }\end{array}$ & 5 years 2 months \\
\hline 2 & Inguinal hernia & 1 month & 5 years 10 months & $\begin{array}{l}\beta \text {-galactosidase } 21.58(\mathrm{NV}>8.5) \\
\alpha \text {-iduronate sulfatase } 0.01(\mathrm{NV}>167) \\
\alpha \text {-hexosaminidase } 1,502.73(\mathrm{NV}>9)\end{array}$ & $\begin{array}{l}443.76 \mathrm{mg} \text { GAGs/g crea (NV } \\
35.74)\end{array}$ & 5 years \\
\hline 3 & $\begin{array}{l}\text { Recurrent upper } \\
\text { respiratory tract } \\
\text { infection }\end{array}$ & 1 year & 5 years & $\begin{array}{l}\text { Leukocyte } \\
\alpha \text {-iduronase } 124.33(\mathrm{NV}>39.7) \\
\alpha \text {-iduronate sulfatase } 0.086(\mathrm{NV}>18) \\
\beta \text {-galactosidase } 141.23(\mathrm{NV}>97.9)\end{array}$ & $\begin{array}{l}535.2210 \text { mg GAGs/g crea } \\
\text { (NV 35.74) }\end{array}$ & 6 years 7 months \\
\hline 4 & Screening & 7 months & 6 years 3 months & $\begin{array}{l}\text { Leukocyte } \\
\alpha \text {-iduronase } 90.98(\mathrm{NV}>39.7) \\
\alpha \text {-iduronate sulfatase } 0.11(\mathrm{NV}>18) \\
\beta \text {-galactosidase } 121.88(\mathrm{NV}>97.9)\end{array}$ & $\begin{array}{l}568.5647 \text { mg GAGs/g crea } \\
\text { (NV 35.74) }\end{array}$ & 1 year \\
\hline 5 & Joint stiffening & 7 years & 8 months & $\begin{array}{l}\text { Leukocyte } \\
\alpha \text {-iduronase } 77.84(\mathrm{NV}>39.7) \\
\alpha \text {-iduronate sulfatase } 0.53(\mathrm{NV}>18) \\
\beta \text {-galactosidase } 118.9(\mathrm{NV}>97.9)\end{array}$ & $\begin{array}{l}778.6195 \text { mg GAGs/g crea } \\
\text { (NV 35.74) }\end{array}$ & 10 years \\
\hline 6 & Coarsening features & 6 years & & & & 6 years \\
\hline 7 & Coarsening features & 6 years & 7 years 10 months & $\begin{array}{l}\beta \text {-galactosidase } 13.74(\mathrm{NV}>8.5) \\
\alpha \text {-iduronate sulfatase } 0.53(\mathrm{NV}>167) \\
\alpha \text {-hexosaminidase } 1,797.05(\mathrm{NV}>9)\end{array}$ & & 7 years 10 months \\
\hline 8 & Coarsening features & 2 years & 6 years 10 months & $\begin{array}{l}\beta \text {-galactosidase } 57.85(\mathrm{NV}>8.5) \\
\alpha \text {-iduronate sulfatase } 0.01(\mathrm{NV}>167) \\
\alpha \text {-hexosaminidase } 1,256.53(\mathrm{NV}>9)\end{array}$ & $\begin{array}{l}692.50 \mathrm{mg} \text { GAGs/g crea (NV } \\
35.74)\end{array}$ & 6 years \\
\hline 9 & Joint stiffening & 3 years & 13 years 6 months & $\begin{array}{l}\beta \text {-galactosidase } 54.25(\mathrm{NV}>8.5) \\
\alpha \text {-iduronate sulfatase } 0.75(\mathrm{NV}>167) \\
\alpha \text {-hexosaminidase } 619.08(\mathrm{NV}>9)\end{array}$ & $\begin{array}{l}363.30 \mathrm{mg} \text { GAGs/g crea (NV } \\
\text { 35.74) }\end{array}$ & 8 years \\
\hline 10 & Joint stiffening & 3 years & 13 years 6 months & $\begin{array}{l}\beta \text {-galactosidase } 51.38(\mathrm{NV}>8.5) \\
\alpha \text {-iduronate sulfatase } 0.21(\mathrm{NV}>167) \\
\alpha \text {-hexosaminidase } 1334.17(\mathrm{NV}>9)\end{array}$ & $\begin{array}{l}629.73 \mathrm{mg} \text { GAGs/g crea (NV } \\
35.74)\end{array}$ & 8 years \\
\hline 11 & Joint stiffening & 3 years & 12 years 8 months & $\begin{array}{l}\beta \text {-galactosidase } 33.39(\mathrm{NV}>8.5) \\
\alpha \text {-iduronate sulfatase } 0.91(\mathrm{NV}>167) \\
\alpha \text {-hexosaminidase } 2,819.33(\mathrm{NV}>9)\end{array}$ & $\begin{array}{l}302.04 \mathrm{mg} \text { GAGs/g crea (NV } \\
\text { 35.74) }\end{array}$ & 8 years 3 months \\
\hline 12 & Coarsening features & 1 year & 3 years 10 months & $\begin{array}{l}\beta \text {-galactosidase } 35.79(\mathrm{NV}>8.5) \\
\alpha \text {-iduronate sulfatase } 0.63(\mathrm{NV}>167) \\
\alpha \text {-hexosaminidase } 2,041.07(\mathrm{NV}>9)\end{array}$ & & 10 years \\
\hline 13 & Inguinal hernia & $1 \frac{1}{1 / 2}$ month & 4 years 6 months & $\begin{array}{l}\beta \text {-galactosidase } 37.70(\mathrm{NV}>8.5) \\
\alpha \text {-iduronate sulfatase } 3.02(\mathrm{NV}>167) \\
\alpha \text {-hexosaminidase } 2,463.64(\mathrm{NV}>9)\end{array}$ & $\begin{array}{l}376.06 \mathrm{mg} \text { GAGs/g crea (NV } \\
45.16)\end{array}$ & 4 years \\
\hline 14 & Coarsening features & 3 years & 9 years 11 months & $\alpha$-iduronate sulfatase $0.525(\mathrm{NV}>167)$ & & 11 years \\
\hline 15 & Developmental delay & 6 years & 22 years 8 months & $\begin{array}{l}\beta \text {-galactosidase } 8.58(\mathrm{NV}>8.5) \\
\alpha \text {-iduronate sulfatase } 1.39(\mathrm{NV}>167) \\
\alpha \text {-hexosaminidase } 457.56(\mathrm{NV}>9)\end{array}$ & $\begin{array}{l}145.35 \mathrm{mg} \text { GAGs/g crea (NV } \\
\text { 35.74) }\end{array}$ & 22 years \\
\hline
\end{tabular}




\section{Skeletal abnormalities}

Progressive arthropathy which consisted of multiple joint contractures, joint stiffness, tight heel cords and claw hand deformity were seen in all patients (Table 2, Figure 4). All of the patients were diagnosed to have multiple joint contractures. One patient had a normal radiographic examination while another showed dysostosis multiplex (Figure 5). The rest were not able to undergo a skeletal survey due to financial constraints. All but two patients were still ambulatory despite the limitations in their joints' range of motion. The two who were not mobile were wheelchair-bound at ages six and ten years. Physical therapy with range of motion exercises were prescribed to all patients. The three patients suspected to have carpal tunnel syndrome were advised splinting.

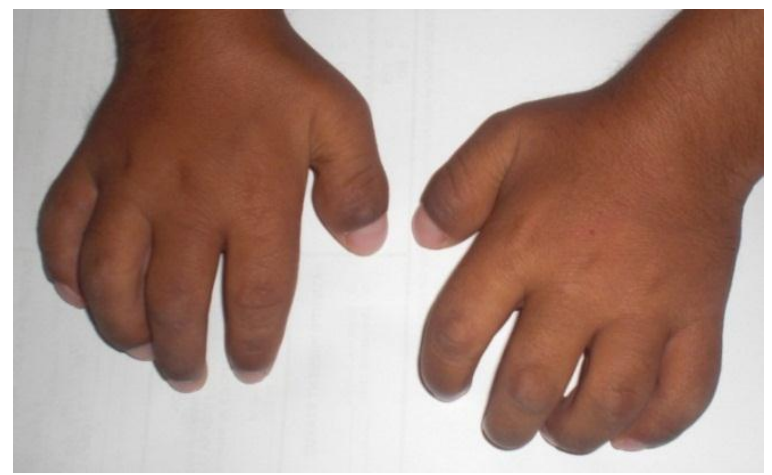

Figure 4. Claw hand deformity of patients with Mucopolysaccharidosis Type II. [Photograph published with consent].

\section{Cardiovascular system}

Eight patients underwent 2D echocardiography. Normal ECHO was found in 1 patient. One patient had a thickened aortic and mitral valve. The most common valvular involvement noted was mitral regurgitation (mild in 4 patients, severe in 1 patient). Other valvular abnormalities noted were mild tricuspid regurgitation (3 patients), mild pulmonic regurgitation ( 2 patients), aortic insufficiency (mild in one patient and mild to moderate in 2 patients), and aortic stenosis (mild in 2 patients, moderate in 1 patient and mild to moderate in 2 patients). Aside from the more common valvular abnormalities, chamber hypertrophy was observed in two patients $(25 \%)$. (Table 2 )

\section{Respiratory and upper airway manifestations}

Progressive airway obstruction was a common finding (73\%). Factors such as recurrent respiratory infections, enlarged tongue and hypertrophic tonsils contributed to this (Table 1). Seven patients had allergic rhinitis, one had bronchial asthma and one had allergic rhinitis with concomitant asthma (Table 2). They were managed by giving anti-histamines and leukotriene receptor antagonists.
Primary snoring and symptoms of obstructive sleep apnea are common complications of airway obstruction seen in our patients. Only three patients underwent polysomnography and are currently on continuous positive airway pressure therapy at night.

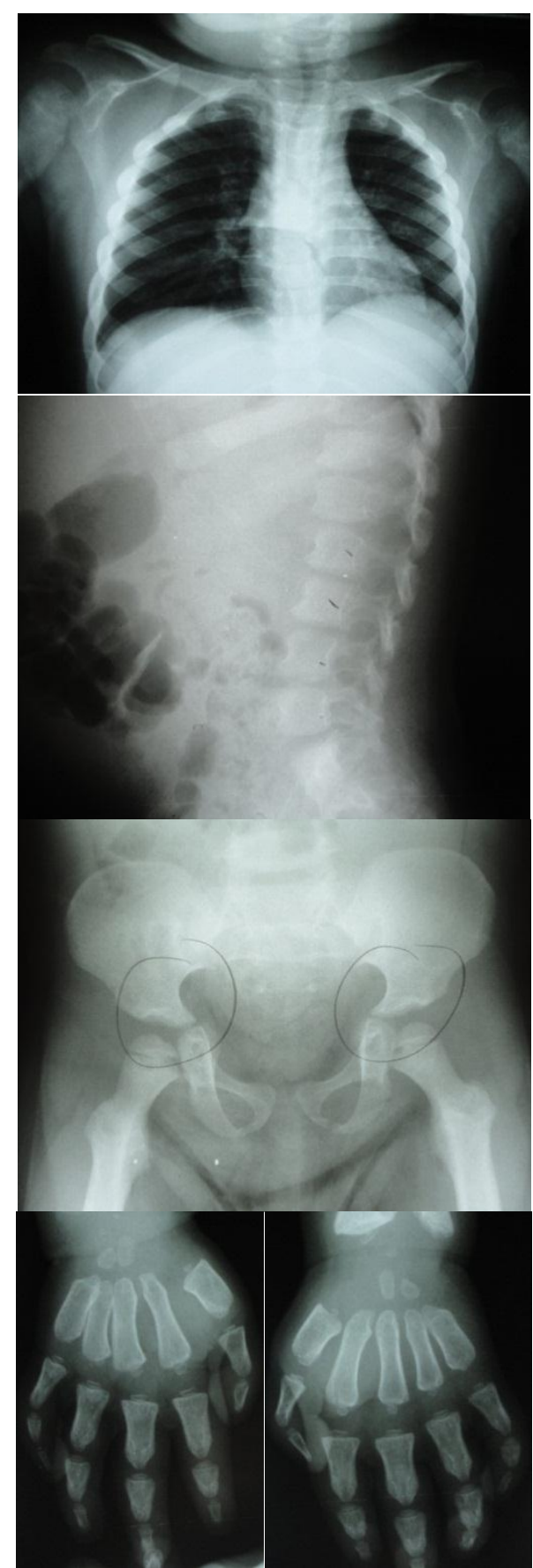

Figure 5. X-ray of a 5-year-old patient with Mucopolysaccharidosis Type II showing dysostosis multiplex (wide clavicles, ribs with canoe paddle appearance, beaked vertebral bodies inferiorly, constricted iliac bones, proximal tapering of metacarpals). 
Table 2. Characteristics of Filipino Patients with Mucopolysaccharidosis Type II

\begin{tabular}{|c|c|c|}
\hline CHARACTERSTIC & $\begin{array}{c}\text { Number of } \\
\text { Patients Affected }\end{array}$ & $\begin{array}{c}\text { Percentage } \\
(\%)\end{array}$ \\
\hline \multicolumn{3}{|l|}{ Physical Appearance } \\
\hline Coarse facial features & $15 / 15$ & 100 \\
\hline $\begin{array}{c}\text { Thickened ala nasi, lips, ear lobules, } \\
\text { tongue }\end{array}$ & $15 / 15$ & 100 \\
\hline Joint contractures & $15 / 15$ & 100 \\
\hline Facial and body hypertrichosis & $14 / 15$ & 93 \\
\hline Abdominal enlargement & $14 / 15$ & 93 \\
\hline Thick and inelastic skin & $14 / 15$ & 93 \\
\hline Pearly papular skin eruptions & $6 / 15$ & 40 \\
\hline Gingival hypertrophy & $5 / 15$ & 30 \\
\hline \multicolumn{3}{|l|}{ Neurologic/Developmental } \\
\hline Mental Retardation, Unclassified & $9 / 15$ & 60 \\
\hline Mental Retardation, profound & $4 / 15$ & 26.7 \\
\hline Developmental regression & $3 / 15$ & 20 \\
\hline Behavioural problems & $3 / 15$ & 20 \\
\hline Seizures & $3 / 15$ & 20 \\
\hline Developmentally at Risk (Normal) & $2 / 15$ & 13.3 \\
\hline $\begin{array}{l}\text { Cerebral atrophy and mild } \\
\text { hydrocephalus on CT Scan }\end{array}$ & $1 / 15$ & 6.7 \\
\hline Spinal cord compression & $0 / 15$ & 0 \\
\hline \multicolumn{3}{|l|}{ Ophthalmologic Findings } \\
\hline Error of Refraction & $6 / 15$ & 40 \\
\hline $\begin{array}{c}\text { Retinal Pigmented Epithelium } \\
\text { changes }\end{array}$ & $3 / 15$ & 20 \\
\hline Glaucoma & $1 / 15$ & 6.7 \\
\hline \multicolumn{3}{|l|}{ Otorhinolaryngology Findings } \\
\hline Enlarged tongue & $10 / 15$ & 67 \\
\hline Hearing impairment & $10 / 15$ & 67 \\
\hline Hypertrophic tonsils & $9 / 15$ & 60 \\
\hline Severe hearing loss & $3 / 15$ & 20 \\
\hline \multicolumn{3}{|l|}{ Respiratory } \\
\hline Sleep apnea & $9 / 15$ & 60 \\
\hline Allergic rhinitis & $7 / 15$ & 46.7 \\
\hline Recurrent URTI & $6 / 15$ & 40 \\
\hline Primary snoring & $5 / 15$ & 30 \\
\hline Bronchial asthma & $1 / 15$ & 6.7 \\
\hline Allergic rhinitis and bronchial asthma & $1 / 15$ & 6.7 \\
\hline Mild mitral regurgitation & $4 / 15$ & 26.7 \\
\hline Mild tricuspid regurgitation & $3 / 15$ & 20 \\
\hline Chamber hypertrophy & $2 / 15$ & 13.4 \\
\hline Mild pulmonic regurgitation & $2 / 15$ & 13.4 \\
\hline Mild to moderate aortic insufficiency & $2 / 15$ & 13.4 \\
\hline Mild aortic stenosis & $2 / 15$ & 13.4 \\
\hline Mild to moderate aortic stenosis & $2 / 15$ & 13.4 \\
\hline Thickened aortic and mitral valve & $1 / 15$ & 6.7 \\
\hline Severe mitral regurgitation & $1 / 15$ & 6.7 \\
\hline Mild aortic insufficiency & $1 / 15$ & 6.7 \\
\hline Moderate aortic stenosis & $1 / 15$ & 6.7 \\
\hline \multicolumn{3}{|l|}{ Abdomen } \\
\hline Hepatosplenomegaly & $13 / 15$ & 86.7 \\
\hline Inguinal hernia & $8 / 15$ & 53 \\
\hline Umbilical hernia & $3 / 15$ & 20 \\
\hline Chronic diarrhea & $0 / 15$ & 0 \\
\hline \multicolumn{3}{|l|}{ Joint } \\
\hline Claw hand deformity & $15 / 15$ & 100 \\
\hline Joint stiffness & $15 / 15$ & 100 \\
\hline Tight heel cords & $14 / 15$ & 93 \\
\hline Multiple Joint Contractures & $14 / 15$ & 93 \\
\hline Carpal tunnel syndrome & $3 / 15$ & 20 \\
\hline Hip dysplasia & $0 / 15$ & 0 \\
\hline
\end{tabular}

Ear, Nose and Throat problems

As previously mentioned, frequent upper respiratory infections occurred in most patients. Hypertrophic tonsils were found in $60 \%$ of patients and only one had hypertrophic adenoids. One patient already underwent tonsillectomy and adenoidectomy at three years of age. One was suspected to have Eustachian tube dysfunction. Most patients had recurrent ear infections and nearly all of them experienced hearing impairment. None had undergone placement of ventilating tubes. Three patients underwent hearing tests which showed severe hearing loss and were given hearing aids. Gingival hypertrophy was seen in five patients $(33 \%)$. (Table 2 )

\section{Gastrointestinal involvement}

Majority of the patients had enlarged liver and spleen $(86.7 \%)$. Inguinal hernia was present in $50 \%$ of patients while umbilical hernia was present in only 3 patients $(20 \%)$. None reported symptoms of recurrent watery diarrhea or malabsorption. (Table 2)

Visual problems

On ophthalmoscopy, 3 patients (ages 10, 12 and 14 years of age) $(20 \%)$ were noted to have retinal pigmentary changes (Table 2). Errors of refraction was seen in 6 patients $(40 \%)$. Three patients wore spectacles. Only 1 patient had glaucoma. Electroretinography was not performed on any of the patients.

\section{Education and behavior}

Most of our patients with the severe type of disease were prescribed rehabilitation therapy; however, due to financial constraints and distance from tertiary hospitals that have this service, only three of them had regular physical and occupational therapy interventions. Likewise, no one went to special schooling. The oldest patient with the attenuated type of disease is currently in his $5^{\text {th }}$ year of college course. Three patients are in mainstream high school and one in elementary. The three patients with behavioral problems are not on any medications.

Anesthetic/Surgical concerns

Two patients are in need of surgical repair for inguinal hernia, three for umbilical hernia and one for gastrostomy insertion. Initial assessment by anesthesiologists for those requiring surgical procedures was done during the clinic. One patient has undergone herniorrhaphy successfully.

\section{Discussion}

All patients demonstrated somatic involvement which included coarse facial features, hepatosplenomegaly, stiff joint and contractures, cardiac valve disease and upper airway obstruction. The most severely affected patients, who include $70 \%$ of our cohort, have profound neurologic 
involvement leading to cognitive impairment and developmental regression. The 5 patients with the more attenuated phenotype also had the same somatic involvement except for the oldest one at 22 years of age who did not present with coarse features and joint stiffening. The typical coarse features are most likely caused by a combination of storage in the soft tissues of the orofacial region and underlying facial bone dysostosis. Storage of GAG in the liver and spleen are likewise thought to explain, at least in part, the hepatosplenomegaly observed in the patients. ${ }^{4}$

The neurologic symptoms seen in our patients are characteristics of the neurologic involvement previously described among MPS II patients. The most prominent feature in our series was cognitive impairment or mental retardation. Not all underwent intelligence testing. However, it has been reported that in general, IQ scores of MPS II patients were found between 42 and 124 with disproportionately bad performance on verbal and reading abilities, which may be attributed to enlarged tongue and impaired hearing. Our clinical observations in these patients are consistent with that range. Severely affected patients achieved their highest cognitive scores at an age of 7 years, whereas in attenuated phenotypes similar to control children, the scores increased progressively with age. ${ }^{5}$ These cognitive effects are the result of GAG accumulation in neural tissues. It has also been proposed that secondary effects such as inflammation may be responsible for the cognitive deterioration observed. ${ }^{1}$ The alterations in behavior such as increased activity level and short attention span are also considered to be due to disruptions brought about by the brain disease. Seizures can also accompany progressive neurologic deterioration, ${ }^{6}$ and can be controlled by anticonvulsant monotherapy., ${ }^{2,4}$

Mucopolysaccharidoses in general are considered to be the most prevalent cause of Carpal Tunnel Syndrome (CTS) in the pediatric age group. ${ }^{7}$ The clinical diagnosis may be difficult to make in the presence of cognitive impairment and consequent lack of a clear history of pain and paresthesia. Our three patients who were suspected to have CTS manifested with pain. Other symptoms reported in literatures included clumsiness, abnormal patterns of grasping or sudden change in playing habits with avoidance of manual activity, nocturnal walking, withdrawal of hands from the touch of others and gnawing of hands. Causes of the development of CTS in patients with MPS II include mucopolysaccharide deposits in the cytoplasm of fibroblasts which inhibit the formation of regular collagen fibers and that soft tissues of the hand may be thickened due to accumulation of mucopolysaccharides within the collagen of tendons, ligaments and joint capsules. ${ }^{6}$ Standard electrophysiological testing will identify median nerve compression even before symptoms appear and should be initiated by age $4-5$ years of age. Decompression surgery is recommended for patients with demonstrated loss of hand function or abnormal nerve conduction studies. ${ }^{2}$

All of our patients exhibited respiratory disease. Progressive deposition of glycosaminoglycans in the soft tissue of the throat and trachea as well as enlargement of the tonsils and adenoids are thought to be responsible for the airway dysfunction and obstruction. The upper airway involvement leads to noisy breathing, particularly at night and is probably a major component of obstructive sleep apnea, which is a common complication in the later stages of the disease. ${ }^{4}$ Apart from other complications, sleep apnea in general cause chronic fatigue or cardiovascular disease. ${ }^{8}$ Thickened epiglottis and narrowed trachea are likewise putative explanations for the obstructive sleep apnea. ${ }^{8}$ Thus, sleep studies should form part of the regular assessment schedule and significant episodes of hypoxia should be managed by continuous positive airway pressure devices. A progressive restrictive respiratory defect also becomes apparent with increasing age, mainly due to progressive changes in the thoracic skeleton. ${ }^{2,8}$

Cardiac disease is present in almost all patients with Hunter Syndrome and is a major cause of death in this population. ${ }^{9}$ It emerges at an early age and is progressive. Nearly two thirds of patients in a recent analysis exhibited important cardiac signs and symptoms. ${ }^{10}$ The most common cardiovascular finding in the said study was valve disease which was present in $63 \%$ of patients. Left ventricular hypertrophy was found in $48 \%$ and elevated blood pressure in $25 \%$ of patients $<18$ years old. Other findings included abnormal heart frequency, arrhythmia and congestive heart failure. Mild mitral regurgitation was the most common cardiac pathology seen in our Filipino patients. The decision to perform surgical valve repair or replacement may be delayed in patients with Hunter syndrome because of the high perioperative risk associated with general anesthesia, primarily because of the morphology of the upper airways that make intubation difficult and post procedural airway edema that may exacerbate airway obstruction. ${ }^{10}$

Hearing loss in Hunter syndrome may be both conductive and sensorineural. Recurrent otitis media is a frequent problem and may lead to conductive hearing impairment. Otosclerotic deformation of auditory ossicles as well as cytoplasmic inclusions in the spiral ganglion has also been reported. PAS positive perivascular mantles indicated GAG storage. ${ }^{11}$ In a recent study data obtained from 554 patients from the Hunter Outcome Survey, ${ }^{12}$ the most prevalent otolaryngological manifestation reported was otitis whether acute or chronic at $72 \%$. Adenoidectomy was done in $47 \%$ and $41 \%$ of children had hearing aids. Audiogram studies showed that $16 \%$ had normal hearing, mild hearing loss in $24 \%$, and moderate in $31 \%$, severe in $22 \%$ and profound in $7 \%$. In our patients, majority had otitis but none underwent ventilation tube placement. Most had severe type of hearing loss. Tonsillectomy and 
adenoidectomy are not yet frequently performed procedures to correct Eustachian tube dysfunction and decrease airway obstruction. However, appropriate regular audiology assessment and provision of correct auditory aids are required. ${ }^{4}$

Although corneal opacity has been reported, it is not generally a feature of younger patients with MPS II and was not seen on any of our patients. In addition, glaucoma is rarely present even in severely affected patients. Only one patient in our series had glaucoma. Six of our patients had errors of refraction. In older patients, retinal pigmentary changes may be seen as well as retinal degeneration resulting in loss peripheral vision and poor dark adaptation. ${ }^{2}$ Since none of our patients underwent electroretinography, the latter feature, however, was not clearly evaluated. It has been suggested that the retina may be the main ophthalmologic focus in MPS II while the visual pathways and striate cortex appear normal. This assertion is supported by the fact that dark adaptation is mainly a function of the retina, and night blindness is a common complaint in Hunter syndrome. ${ }^{13}$ However, clinically, it is also important to consider optic atrophy, papilledema and scotoma. Disc elevation was seen in nearly $20 \%$ of mucopolysaccharidoses and $10 \%$ presented with or developed optic atrophy. It seemed that optic atrophy followed the development of nerve head swelling which may be a consequence of increased intracranial pressure, retinal degeneration, GAG accumulation on ganglion cells or direct compression of the optic nerve axons by thickened sclera. ${ }^{5}$ Routine ophthalmologic eye care is suggested and if disk swelling is discovered due to elevated CSF pressure, shunting may be indicated. ${ }^{2}$

Orthopedic involvement is common in patients with MPS II and leads to severe restrictions in motion and impaired quality of life. Musculoskeletal manifestations reported include arthropathy, contractures and joint stiffness, claw hands, carpal tunnel syndrome, short limb length and deformities in the bones of the spine, chest and limbs. Spinal cord compression may also occur either as a result of spine deformities or due to soft tissue involvement. All of our patients mainly presented with short stature and 93\% were noted to have joint contractures leading to limited ranges of motion. A combination of inflammation, activation of fibroblasts, disturbances in cartilage and bone, and increased skin thickness are thought to be the cause of contractures. Cellular and physiological mechanisms resulting in the musculoskeletal manifestations of mucopolysaccharidoses in general include high GAG accumulation in cartilage, bone and connective tissues. In animal models of MPS disorders, GAG accumulation stimulates proliferation of synoviocytes and immune cells, and promotes infiltration of the latter into various connective tissues. In addition, articular chondrocytes have been found to undergo a high rate of apoptosis, which increases with age and is associated with destructive processes in the joints. Chondrocyte death is compounded by the mechanical forces placed on the deformed joints and spine, which leads to inflammatory response and matrix abnormalities, causing further destruction of cartilage and bone. ${ }^{7}$ In the HOS data on skeletal abnormalities, $79 \%$ of patients had skeletal manifestations with median onset at 3.5 years and $25 \%$ had abnormal gait. Joint range of motion was restricted for all joints assessed, and extension was the most severely affected movement. Surgery for orthopedic problems was rare. ${ }^{7}$

The number and severity of clinical manifestations among our patients did not show a significant correlation with the levels of urinary GAGs nor with the I2S activity. Also, no significant correlation was found between the levels of urinary GAGs and the I2S activity. These observations conform with the previously reported finding that neither the amount of I2S nor its activity, as determined by routine diagnostic tests correlates with phenotype severity in patients with Hunter syndrome. ${ }^{1,2}$ Likewise, the analysis of urine GAG composition cannot be used to discriminate between subtypes of MPSs including MPS II. ${ }^{1}$

There was a significant delay between the onset of signs and symptoms and the diagnosis of MPS II in the Philippines. These findings may be associated with the lack of awareness among local physicians about the disease and the inaccessibility of biochemical diagnostic tests that will confirm the disorder. Thus, programs and activities that will further increase the awareness about this disorder should be implemented to facilitate early diagnosis and address promptly the problems associated with Hunter syndrome.

\section{Conclusion}

Filipino patients with Hunter syndrome exhibit the characteristic multi-organ involvement seen in most patients with the disorder, thus, their management requires a multidisciplinary approach. Routine follow up by different subspecialties mentioned above are vital in terms of monitoring of the disease manifestations, disease progression and how these may affect treatment decisions or require special considerations. However, achieving this systematic follow-up is difficult in most of our families who are financially constrained.

Counseling and psychosocial support are likewise essential resources to offer patients with MPS II and their families who must live day to day with the devastating and progressive complications of the disease.

The one stop multidisciplinary clinic in our hospital was thus established to provide patients with care that encompasses their problems in toto and consequently help in giving these children a comfortable and acceptable quality of life despite limited therapeutic options. Likewise, maintaining contact with other families through the clinic 
help them cope with feelings of isolation and despair. An organization like the Philippine Society for Orphan Disorders similarly frequently visits the clinic and provide help and support to the families.

\section{Acknowledgments}

The authors are grateful for the assistance of the Genetic Metabolic team (Dr. Sylvia Estrada, Aster Lynn Sur, Angela Villa), Dr. Paul Hwu and Laurah Yeh of National Taiwan University Hospital, Dr. Aleth Sia, Section of Developmental Pediatrics (Dr. Alexis Reyes), Section of Neurology (Dr. Marissa Lukban), Section of Pediatric Pulmonology (Dr. Ces Galang), Section of Pediatric Cardiology (Dr. Dexter Cheng), Department of Ophthalmology (Dr. Pearl Villalon), Department of Otorhinolaryngology (Dr. Ronald Reyes), Department of Surgery Section of Pediatric Surgery (Dr. Esther Saguil), Department of Rehabilitation Medicine (Dr. Cynthia Ang), Department of Anesthesiology (Dr. Katherine Reyes) and all the residents and fellows of each department who attended to the children in the clinic.

\section{References}

1. Martin R, Beck M, Eng C, et al. Recognition and diagnosis of mucopolysaccharidosis II (Hunter syndrome). Pediatrics. 2008; 121(2):e377-86.

2. Muenzer J, Beck M, Eng CM, et al. Multidisciplinary management of Hunter syndrome. Pediatrics. 2009; 124(6):e1228-39.
3. Scarpa M, Almássy Z, Beck M, et al. Mucopolysaccharidosis type II: European recommendations for the diagnosis and multidisciplinary management of a rare disease. Orphanet J Rare Dis. 2011; 6:72.

4. Wraith JE, Scarpa M, Beck M, et al. Mucopolysaccharidosis type II (Hunter syndrome): a clinical review and recommendations for treatment in the era of enzyme replacement therapy. Eur J Pediatr. 2008; 167(3):267-77.

5. Al Sawaf S, Mayatepek E, Hoffman B. Neurological findings in Hunter disease: pathology and possible therapeutic effects reviewed. J Inherit Metab Dis. 2008; 31(4):473-80.

6. Holt J, Poe MD, Escolar ML. Early clinical markers of central nervous system involvement in mucopolysaccharidosis type II. J Pediatr. 2011; 159(2):320-6.

7. Link B, de Camargo Pinto L, Giugliani R, et al. Orthopedic manifestations in patients with mucopolysaccharidosis type II (Hunter syndrome) enrolled in the Hunter Outcome Survey. Orthop Rev. 2010; 2(2):e16.

8. Shapiro J, Strome M, Crocker AC. Airway obstruction and sleep apnea in Hurler and Hunter syndromes. Ann Otol Rhinol. 1985; 94(5 Pt 1):45861.

9. Braunlin EA, Harmatz PR, Scarpa M, et al. Cardiac disease in patients with mucopolysaccharidosis: presentation, diagnosis and management. J Inherit Metab Dis. 2011; 34(6):1183-97.

10. Kampmann C, Beck M, Morin I, Loehr JP. Prevalence and characterization of cardiac involvement in Hunter syndrome. J Pediatr. 2011; 159(2):327-31.

11. Hayes E, Babin R, Platz C. The otologic manifestations of mucopolysaccharidoses. Am J Otol. 1980; 2(2):65-9.

12. Keilmann A, Nakarat T, Bruce IA, Molter D, Malm G; HOS Investigators. Hearing loss in patients with mucopolysaccharidosis II: data from HOS - the Hunter Outcome Survey. J Inherit Metab Dis. 2012; 35(2):343-53.

13. Ashworth JL, Biswas S, Wraith E, Lloyd IC. Mucopolysaccharidoses and the eye. Surv Ophthalmol. 2006; 51(1):1-17

UP Manila National Graduate Office for the Health Sciences (NGOHS)

Tel nos: (02)526-5870, (02)523-1495 Telefax: 523-1498

Email: ngohs@post.upm.edu.ph

\section{Now accepts applicants for the MASTERS OF SCIENCE IN GENETIC COUNSELING PROGRAM}

MS Genetic Counseling is a two-year degree program under the Department of Pediatrics, College of Medicine that prepares students to become competent genetic counselors who will serve a vital role in the access, delivery, and expansion of medical genetics in the country.

\section{Deadline: April 5, 2013}

Application forms and list of requirements may be obtained from NGOHS website at www.ngohs.upm.edu.ph.

Scholarships are also available for the students of this program. Limited slots only. Please inquire at: (02)310-3957. 